\title{
Variáveis do Terapeuta: Análise em Periódicos Brasileiros (1998-2007)
}

\author{
Emérico Arnaldo de Quadros" \& Elisa Medici Pizão Yoshida
}

Pontifícia Universidade Católica de Campinas, Campinas, Brasil

\begin{abstract}
RESUMO
Apesar do reconhecimento da relevância do papel do psicoterapeuta no atendimento psicológico, não é claro como as variáveis relacionadas a ele atuam sobre o processo. Este estudo visou conhecer o que foi pesquisado sobre o terapeuta no Brasil, realizou-se levantamento em periódicos brasileiros, Qualis A e B, entre 1998 a 2007. Foram analisadas variáveis formais da produção e as variáveis pesquisadas do terapeuta, divididas em: traços e estados observáveis e inferidos. A amostra de 45 artigos foi acessada em 22 periódicos, no portal CAPES e bibliotecas. Os resultados apontaram para pouca produção de pesquisas empíricas $(29 \%)$ e predomínio de trabalhos teóricos $(60 \%)$. Os resultados sugerem que a maioria das variáveis que são objeto de pesquisa na literatura internacional são ignorada ou apenas mencionada nos trabalhos nacionais. As conclusões remetem à necessidade de mais pesquisas brasileiras voltadas para as variáveis do terapeuta.
\end{abstract}

Palavras-chave: pesquisa em psicoterapia; pesquisa de resultado em psicoterapia; processo de psicoterapia.

\begin{abstract}
Therapist Variables: An Analysis in Brazilian Journals (1998-2007)

Despite the recognition of the psychotherapist relevance in psychological treatment, it is not yet clear how the therapist variables act in the process of treatment. The present study aimed to investigate research about the therapist variables in Brazil by reviewing Brazilian Journals, Qualis A or B, from 1998 to 2007 . We analyzed formal production variables and the therapist researched variables. They were divided in: observable and inferred traits and observable and inferred states. The sample consisted of 45 articles, from 22 national journals, accessed in CAPES website and libraries. The results suggested a poor production of empirical researches $(29 \%)$ and predominance of theoretical works $(60 \%)$. The majority of the variables researched in the international literature are ignored or just mentioned in national works. Conclusions point to the necessity of more Brazilian researches on therapist variables.
\end{abstract}

Keywords: psychotherapy research; outcome psychotherapy research; psychotherapy process.

A maior parte das pesquisas ligadas aos processos psicoterapêuticos está direcionada para a investigação das intervenções técnicas usadas pelos psicoterapeutas, muito embora de forma menos frequente apareçam também pesquisas relacionadas à complexa participação que o terapeuta tem no processo. Beutler et al. (2004) ressaltam que aspectos ou variáveis ligadas à pessoa do terapeuta estão associados e muitas vezes são preditores dos resultados de psicoterapias.

Ceitlin, Wiethaeuper e Goldfeld (2003) apontam que as considerações e hipóteses ligadas ao terapeuta são confirmadas por três tipos de resultados observados nas pesquisas: 1) os benefícios terapêuticos estão mais associados à pessoa do terapeuta do que à sua abordagem teórica; 2) alguns terapeutas produzem melhores resultados do que outros; 3) existem terapeutas que produzem efeitos negativos no desfecho do tratamento. Estes dados empíricos se contrapõem à visão que se tinha até algum tempo atrás, de que o terapeuta era uma figura neutra que buscava basicamente não interferir com seus valores, crenças, enfim com sua própria pessoa no processo psicoterapêutico e na direção da cura. Eles também não chegam a ser

\footnotetext{
Endereço para correspondência: Emérico Arnaldo de Quadros - earnaldo@onda.com.br.
} 
consensuais. Na verdade, a produção acerca de variáveis do terapeuta é bastante ampla e heterogênea, muitas vezes com resultados conflitantes e contraditórios.

Outro ponto a ser destacado refere-se aos critérios para a classificação das variáveis do terapeuta que detêm importância sobre o processo terapêutico e/ou sobre o seus resultados. Beutler, Machado e Neufeldt (1994), por exemplo, na quarta edição do clássico Bergin and Garfield's Handbook of Psychotherapy and Behavior Change, classificaram as variáveis em quatro quadrantes representados por duas dimensões que se interceptavam. A primeira dimensão distribuía as respostas do terapeuta entre um pólo que enfatizava os traços do terapeuta (extraterapia - em que entram as qualidades do terapeuta enquanto pessoa) e, outro, mais voltado para os estados do terapeuta (as variáveis empregadas, desenvolvidas ou definidas especificamente para promover seu papel de psicoterapeuta). Quanto à segunda dimensão, distribuía as variáveis entre objetivas e subjetivas. No entanto, os termos utilizados para o emprego desta dimensão eram pouco claros, o que levava a pouco discernimento das variáveis avaliadas.

Procurando superar esta dificuldade, na quinta edição do Bergin and Garfield's Handbook (Lambert, 2004), Beutler et al. (2004) propuseram uma revisão da dimensão objetiva-subjetiva, substituindo-a por observável-inferida. De acordo com os autores, as qualidades observáveis podem ser registradas e avaliadas por procedimentos tais como, observação direta, uso de gravação e/ou parecer colateral. Entre elas incluem-se, por exemplo, o sexo do terapeuta, faixa etária (jovem, adulto jovem, idoso) e intervenções usadas. Já as qualidades inferidas incluem aspectos da personalidade e qualidade de relacionamento que são capazes de serem percebidas apenas por meio de informações fornecidas pelo próprio terapeuta (ex. gênero, crenças religiosas, postura teórica). Isto é, são qualidades que só podem ser indiretamente acessadas pelo observador e que podem ser de natureza genética, congênita ou adquirida. Dentro desse referencial temse então: Traços observáveis (ex. sexo idade, etnia); Estados observáveis (ex. treinamento do terapeuta, supervisão como forma de aprendizagem, experiência, classes de intervenção); Traços inferidos (personalidade do terapeuta, bem estar emocional do terapeuta, valores e crenças e atitudes culturais); Estados inferidos (orientação teórica do terapeuta, flexibilidade, valores atitudes e crenças).
A supervisão, um estado observável, é considerada a melhor maneira de aprendizado da psicoterapia clinica, neste sentido, Foster, Lichtenberg e Peyton (2007), dizem que existe uma experiência de supervisor positiva quando os supervisores são suportivos e instrucionais, sendo que o desejo ou necessidade de um supervisor suportivo está sempre presente na supervisão. Conceitualmente supervisão provoca uma mudança emocional no comportamento do supervisionado, explanando suas repostas mal-adaptativas ou inapropriadas. Os autores propõem três níveis para o desenvolvimento do supervisionado, a cada um desses níveis há uma correspondência do supervisor. Nível 1 - os supervisionados têm limitado conhecimento e isso requer um alto nível de estrutura e sensibilidade do supervisor. Nível 2 - supervisionados estão em estado de tensão entre a autonomia e dependência e requerem flexibilidade do supervisor e nível 3 - estudantes têm um sólido conhecimento das bases teóricas requerendo então mais suporte do que observações fechadas. Os autores concluem que um grande entendimento do processo de supervisão é de interesse do desenvolvimento do treinamento e da qualidade do serviço prestado.

A meta efetiva da supervisão segundo Hess et al. (2008), é o desenvolvimento nos supervisionados de conhecimentos clínicos e identidade profissional e também prover ética e efetividade no tratamento dos clientes. A qualidade do relacionamento na supervisão, o estilo pessoal do supervisor e o papel dos supervisionados, além do alto-risco com que os supervisionados colocam uma evolução negativa do caso, poderá levar o supervisionando a uma postura de não se revelar na supervisão.

Sobre a orientação teórica dos terapeutas, Roussos, Lissin e De Duarte (2007) realizaram estudo sobre a importância da formação teórica na formulação de inferências clínicas em psicoterapia observaram que os terapeutas de linha psicodinâmica focalizaram suas sessões no passado do cliente, já os de linha cognitiva concentraram-se no "como" os clientes poderão lidar mais efetivamente com os eventos no futuro. $\mathrm{O}$ estudo não indica se estas diferenças se refletiram nos resultados da terapia. Já Tryon, Blackwell e Hammel (2007) argumentam que a terapia comportamental dá importância à colaboração cliente-terapeuta, focando a modificação da cognição do cliente para os comportamentos disfuncionais. A psicoterapia psicodinâmica, em contraste, mantém seu foco no relacionamento do 
cliente com o terapeuta, particularmente na interpretação da transferência do cliente.

Com relação à religião do terapeuta e intervenções feitas pelo mesmo, Wade, Worthington e Vogel (2007) após realizarem pesquisa acreditam que as intervenções religiosas sob medida são apropriadas. Já Smith, Bartz e Richards (2007) realizaram uma meta-análise com 31 estudos sobre terapias com orientação religiosa e encontraram resultados que sugerem que a orientação espiritual na terapia beneficia indivíduos com determinados problemas psicológicos (por ex. depressão, ansiedade, stress, desordens alimentares), sendo um campo a ser mais pesquisado.

Williams e Levitt (2008), em pesquisa onde estudam valores e multiculturalismo no processo terapêutico, defendem que existem evidências empíricas indicando que terapeutas não conseguem ter neutralidade e rotineiramente transmitem seus valores para os clientes.

Como pode ser observado, existem muitos fatores a serem investigados no que diz respeito à pessoa do terapeuta. Vários estudos, existentes na literatura internacional, tiveram como objetivo a revisão sistemática da área para definir seu atual estado e identificar, entre outras coisas, o que já pode ser considerado consenso e quais seriam os desafios a serem enfrentados (por ex. Lambert, 2007; Timulak, 2007). Na literatura nacional, a despeito de já haver uma produção relativamente numerosa voltada para a pesquisa das variáveis do terapeuta e do número crescente de terapias, não foram encontrados estudos que envolvessem uma análise sistemática da produção brasileira. Considerando que as variáveis relacionadas à pessoa e à cultura do terapeuta (entre as quais se encontram, por exemplo, o sistema de valores, a língua, o contexto histórico e social, entre várias outras) podem ter grande peso no desenvolvimento e na forma do processo terapêutico, assim como nos seus resultados, considerou-se relevante realizar uma pesquisa da produção científica brasileira, para conhecer como as variáveis do terapeuta têm sido estudadas e em que medida encontram-se ou não alinhadas com os resultados dos estudos internacionais. Para tanto, foram definidos como objetivos, a realização de um levantamento da produção científica, em periódicos brasileiros classificados como Qualis A e B, no período de 1998 a 2007, com foco sobre as variáveis do psicoterapeuta. A análise do material levantado procurou basicamente identificar quem tem pesquisado as variáveis do terapeuta (autores e filiação institucional), onde ela pode ser encontrada (periódicos), o tipo do trabalho (empírico ou teórico) e que variáveis do terapeuta têm sido focalizadas.

A opção pela busca eletrônica (embora alguns artigos tenham sido achados nas bibliotecas nacionais) se deve à facilidade de acesso a um número expressivo de trabalhos, o que garante uma amostra representativa da produção, bem como o potencial de impacto de informações ali constante em face à visibilidade que apresenta (Yoshida, Santeiro, Santeiro \& Rocha, 2005). A opção pelos últimos 10 anos de produção levou em consideração a atualização e consistência, já que dez anos podem mostrar quais situações, envolvendo a variável, persistiram.

\section{MÉTODO}

\section{Amostra}

A amostra ficou constituída por 45 artigos publicados em 22 periódicos, classificados como Qualis $A$ (nacional e internacional) e Qualis B, no sistema de classificação Qualis - área de Psicologia, Psiquiatria e Psicanálise, do portal de periódicos da CAPES (CAPES - Triênio 2004-2006). O acesso aos artigos foi realizado utilizando-se os descritores: variáveis do terapeuta, psicoterapeuta, etnicismo, gênero, idade, sexo, transferência, contratransferência, religião e psicoterapia.

\section{Instrumento}

Com base nas categorias utilizadas por Beutler et al. (2004), foi elaborado um Formulário para Classificação dos Artigos, composto pelas seguintes categorias: 1. Variáveis do psicoterapeuta: a) Traços observáveis: sexo, idade e raça do terapeuta; etnia; b) Estados observáveis: quantidade de treinamento (terapeuta experiente, não experiente), categoria profissional (psiquiatra, psicólogo, outro), método de tratamento (uso de manuais de treinamento, supervisão), classes de intervenção (centrado no sintoma, insight, enfoque sobre emoções, outras); c) Traços Inferidos: bem estar emocional do terapeuta, busca de psicoterapia, valores culturais, morais ou religiosos, atitudes gerais (gênero do terapeuta, etnicidade do terapeuta $v s$. do paciente; d) Estados Inferidos: Modelo teórico (psicanálise ou psicodinâmica; comportamental e/ou cognitivista, humanista, mais de um, outro), contratransferência (em trabalhos de linha psicanalítica ou psicodinâmica), tipo de serviço atendimento (clínica particular ou 
atendimento em saúde pública); 2. Tipo do trabalho: empírico, teórico, relato de experiência, caso clínico, revisão de literatura (Santeiro, 2005).

\section{Procedimento}

Com base nos descritores citados, foram encontrados 348 artigos, no Portal de Periódicos da Capes. Desses, nem todos podiam ser acessados na íntegra a partir da Internet, por tal razão procedeu-se à sua procura nas bibliotecas nacionais. A leitura dos mesmos indicou que, destes, apenas 45 tinham como objetivo do trabalho o psicoterapeuta, propriamente dito.

Para a estimativa da fidedignidade das avaliações realizadas, uma amostra de 10 artigos (cerca de $20 \%$ da amostra total) foi avaliada por dois juízes independentes. Após a leitura de cada artigo, cada juiz preenchia o Formulário para Classificação dos Artigos. O grau de acordo entre os juízes foi dado pelo cálculo do kappa de Fleiss (adequado a avaliações de dois juízes). Valores positivos de $\mathrm{k}$ significam sempre a existência de grau de concordância entre os juizes sendo a intensidade da concordância proporcional à proximidade com o valor 1; ou seja, para casos em que $\mathrm{k}=1$ a concordância é total, para $\mathrm{k}=0$ a concordância poderia ter sido obtida meramente ao acaso e para $\mathrm{k}$ negativos não há concordância entre os juízes. É importante ressaltar que quando negativo o valor absoluto não reflete a intensidade da discordância apenas a sua existência. Ex: k=-1,2 e k=-0,001 apenas representam discordância entre os juízes com relação àquela questão e não que haja uma maior ou menor discordância. De maneira geral pode-se dizer que para $0 \leq \mathrm{k} \leq 0,2$, a concordância é tênue; $0,21 \leq \mathrm{k} \leq 0,4$ a concordância é moderada; $0,41 \leq \mathrm{k} \leq 0,6$ a concordância é média; $0,61 \leq \mathrm{k} \leq 0,8$ a concordância é forte; $0,81 \leq \mathrm{k}<1$ a concordância é fortíssima e para $\mathrm{k}=1$ a concordância é perfeita (Fleiss, 1981). Os valores de kappa e o nível de concordância são apresentados na Tabela 1. Para concordâncias "Tênue e Moderada" foi adotado o critério de avaliação consensual. Isto é, os juízes discutiram as avaliações e chegaram a um consenso.

Tabela 1

Valores de Kappa e Nivel de Concordância Entre os Juízes

\begin{tabular}{l|l|l}
\hline Categoria & Kappa & Nível de concordância \\
\hline Natureza do trabalho & 0,2907 & . Moderada \\
\hline Traços observáveis & 0,1578 & . Tênue \\
\hline Estados observáveis & 0,1667 & . Tênue \\
\hline Métodos de tratamento & 1,0000 & . Perfeita \\
\hline Competência do terapeuta & 1,0000 & . Perfeita \\
\hline Bem-estar emocional & 0,3814 & . Moderada \\
\hline Valores & 0,6552 & . Forte \\
\hline Atitudes gerais & 0,6226 & . Forte \\
\hline Modelo teórico de trabalho & 0,7015 & . Forte \\
\hline Contratransferência & 0,5833 & . Média \\
\hline Tipo de serviço de atendimento & 0,4393 & . Moderada \\
\hline
\end{tabular}

\section{RESULTADOS}

Com a finalidade de tornar mais clara a exposição dos resultados, inicia-se pelas variáveis relacionadas ao periódico, autores, filiação institucional. A seguir, são apresentados os resultados do segundo objetivo específico, Natureza do Trabalho. E, finalmente, as variáveis do psicoterapeuta.
Os 45 artigos que compuseram amostra distribuíram-se por periódicos Qualis A nacional e internacional e Qualis B nacional como se segue: $68,18 \%$ classificados como Qualis A - nacional ( $\mathrm{n}=15) ; 13,63 \%$ como Qualis A - Internacional $(\mathrm{n}=3)$ e 18, 8\% Qualis $B$ Nacional $(\mathrm{n}=4)$. Do total de periódicos $(\mathrm{n}=22)$, cinco respondem por quase $50 \%$ dos artigos. Sendo os três de maior frequência, o Psychê $(11,1 \%)$, o Pulsio- 
nal $(11,1 \%)$ e Revista de Psiquiatria do Rio Grande do Sul $(11,1 \%)$, que perfazem $33,3 \%$ dos artigos. A seguir aparecem, o periódico Estudos de Psicologia (Campinas) (8,9\%) e o Psicologia: Ciência e Profissão $(6,7 \%)$. Outros periódicos incluídos na amostra foram: Agora (2,2\%), Aletheia (2,2\%), Arquivos Brasileiros de Psicologia (2,2\%), Estudos de Psicanálise (2,2\%), Interações $(2,2 \%)$, Natureza Humana $(4,4 \%)$, Psicologia Clínica (4,4\%), Psicologia em Revista (2,2\%), Psicologia Reflexão e Crítica (2,2\%), Psicologia USP $(4,4 \%)$, Psicologia: Teoria e Pesquisa $(2,2 \%)$, Psicologia: Teoria e Prática (4,4\%), Reverso 4,4\%), Revista Brasileira de Psicoterapia (2,2\%), Revista Brasileira de Terapia Comportamental Cognitiva (2,2\%), Revista Mal Estar e Subjetividade (2,2\%), Revista PsicVetor $(2,2 \%)$.

Em relação à autoria, 53,3\% artigos $(n=24)$ eram de um único autor, enquanto os demais $(46,7 \%)$ escritos em coautoria, por 55 autores. Os trabalhos em coautoria variaram entre dois e oito autores. O tipo mais frequente foi de dois autores $(62 \%)$, seguido do de três autores $(24 \%)$. Os autores estão distribuídos por 28 instituições (Moda= 5, Mediana 1), sendo que apenas seis possuem mais de um autor $(21,4 \%)$. São essas instituições as seguintes: UFRGS (cinco autores), PUC-RJ (quatro autores), USP (quatro autores); PUC-Goiás (três autores), PUC-SP (três autores), UNICAP - Universidade Católica de Pernambuco (dois autores). Em relação ao número de autores por instituição, a distribuição é bimodal, Moda 5 e a Mediana 1.

Considerando a relação instituição/artigo, os autores de sete instituições produziram mais de um artigo, de tal forma que eles são responsáveis pela produção de 24 artigos, ou seja, 53,3\% do total da amostra. O número de artigos publicados por instituição teve média de 2,10 e desvio padrão de 1,22. E as Instituições com mais de um artigo escrito foram também as que tiveram mais autores. São elas: UFRGS (cinco artigos), PUC-RJ (quatro artigos); USP (cinco artigos), PUC Goiás (três artigos), PUC SP (três artigos), UNICAP (dois artigos). Além delas há o Círculo Psicanalítico de Minas Gerais, com dois artigos.

A estimativa do coeficiente de correlação entre autores por instituição e número de artigos escritos por instituição indicou forte associação entre estas variáveis $(r=0,932)$. As instituições foram divididas em: Pública, Particular e Outras (por exemplo, Sociedades de Psicanálise, Associações de Psicologia, Fundações de Ensino no exterior). Tanto as instituições de ensino superior público $(37,8 \%)$, quanto às instituições particulares $(37,8 \%)$, tiveram o mesmo nível de produção. Cabe ressaltar o papel das Universidades da rede particular principalmente as Pontifícias Universidades Católicas, que têm tradição de pesquisa, encontrandose aí a PUC-SP, PUC-Campinas, PUC-RJ e Universidade Católica de Goiás.

Quanto à participação ou não dos primeiros autores em grupos de pesquisa, $65 \%$, pertence a grupos de pesquisa do $\mathrm{CNPq}$, o que mostra que a iniciativa do CNPq está de fato cumprindo seus objetivos, que é o de promover estímulo à pesquisa científica e tecnológica e à formação de recursos humanos para pesquisa no país como também maior intercambio entre os pesquisadores. Os autores que participam de grupos de pesquisa e que publicaram em periódicos com Qualis A (nac. + int.) são em número de 23, o que leva a pensar que o fato de estar vinculado a instituições e associações que têm grupos de pesquisa atuantes, leva a uma produção de melhor qualidade.

Os artigos foram classificados em: estudo empírico, trabalho teórico, relato de experiência, trabalho teórico ilustrado por caso clínico e revisão de literatu$\mathrm{ra}$, segundo as definições propostas por Santeiro (2005). A maior concentração (60\%) dos trabalhos é de cunho teórico, quando se reúne trabalhos teóricos $(33,3 \%)$ e trabalho teórico ilustrado por caso clínico $(26,7 \%)$. A seguir aparecem os estudos empíricos $(28,9 \%)$, relato de experiência $(8,9 \%)$ e revisão de literatura $(2,2 \%)$.

Quanto às variáveis do psicoterapeuta é preciso esclarecer que as variáveis foram computadas, sempre que havia ao menos menção a elas. Isto significa que, não necessariamente, esta variável foi, especificamente, objeto do estudo. Em 57,8\% dos artigos foi feita referência aos Traços Observáveis ligados à pessoa do terapeuta, sendo que a maioria mencionava a variável sexo do terapeuta $(31,1 \%)$. O percentual de estudos envolvendo unicamente a variável sexo do terapeuta foi superior à soma das frequências de todas as outras variáveis estudadas. As variáveis etnia e idade ou faixa etária do terapeuta (isolada) apresentaram a mesma frequência de estudos, ou seja, 6,7\% cada. Grande parte dos artigos (42,2\%) não mencionou nenhum traço observável do terapeuta.

Quanto às variáveis classificadas como Estados Observáveis, em $77 \%$ dos artigos $(\mathrm{n}=35)$ apareciam a quantidade de treinamento e experiência do terapeuta. 
Com relação à experiência do terapeuta, em 11,1\% dos artigos os terapeutas foram vistos como inexperientes. Em geral em artigos que tratavam do processo de aprendizado da clínica ou ligados à supervisão de alunos de último ano de psicologia. Quanto à formação profissional do terapeuta, isto é, se o terapeuta era psicólogo, psiquiatra, conselheiro ou outro, não foi encontrado nenhum artigo mostrando profissionais diferentes de psicólogos ou psiquiatras. As variáveis categorizadas como Métodos de Tratamento incluíam uso de manual de treinamento, supervisão e uso de manual de tratamento e supervisão. A Supervisão (se o terapeuta faz ou busca supervisão, ou mesmo se é supervisor) é tida como a principal forma de aprendizagem da técnica de tratamento $(57,8 \%)$ já o uso de manuais de treinamento é pouquíssimo citado, $(2,2 \%)$. Enquanto a utilização apenas do Manual de treinamento é citada em um artigo, três artigos citam o uso do referido manual, porém, com o acréscimo de supervisão. Ressalte-se que em nenhum estudo o manual ou sua aplicação foi objeto de estudo. Com relação à competência do terapeuta, estes são definidos como competentes por Beutler et al. (2004) como os que apresentam habilidade nos procedimentos e aplicação do tratamento, que $55,5 \%$ dos artigos enfatizaram de alguma forma a competência do terapeuta, seja através de declarações feitas pelos psicólogos entrevistados em pesquisas que compuseram a amostra, pelo tempo de formação dos terapeutas ou pelas intervenções utilizadas entre outras formas.

Em relação às variáveis categorizadas como Traços Inferidos, o bem estar emocional do terapeuta foi avaliado pela referência de que o terapeuta tinha ou deveria buscar psicoterapia, e apareceu em $62,2 \%$ dos artigos. Dentre os de orientação psicanalítica, parece haver um consenso de que a formação do psicanalista passa pela supervisão, estudo teórico e busca de análise pelo próprio terapeuta. Quanto aos valores significativos e crença religiosa ligados ao terapeuta, $64,4 \%$ dos artigos situam valores éticos (solidariedade, honestidade, verdade, lealdade, bondade, altruísmo), estéticos (harmonia, belo, sublime, trágico), políticos (justiça, igualdade, imparcialidade, cidadania, liberdade). Os artigos mostram pouco interesse $(13,3 \%)$ por atitudes gerais, nas relações entre variáveis como gênero e etnia do terapeuta e aquela do paciente.

Quanto aos Estados Inferidos, a maioria dos artigos $(71,1 \%)$ situa o modelo teórico psicodinâmico, seguido do cognitivista e comportamental com frequência idêntica $(8,9 \%)$, Humanista $(4,4 \%)$, Mais de um (Psicanálise e cognitivista/Psicanálise e Humanista) também com 4,4\% e outros modelos (Psicodrama de Moreno) com 2,2\%. Os resultados demonstram ainda que $80 \%$ dos artigos identificaram a contratransferência (equivalente teórico a variáveis do terapeuta na literatura psicanalítica) e $20 \%$ não a situaram. Alguns artigos mesmo não tendo a abordagem psicanalítica falam indiretamente da contratransferência, como é o caso de Braga e Vandenberg (2006), onde aparecem as reações comportamentais do terapeuta aos comportamentos do paciente.

\section{DISCUSSÃO}

Pensando-se na quantidade de variáveis que foram objeto de estudo, cada uma delas, por si, é factível de um desenho de pesquisa, propondo ou sugerindo pesquisas que venham responder a questionamentos dentro da realidade brasileira de situações que também, a partir dos anos 70 do século passado vem incomodando pesquisadores e profissionais em outros países.

Os periódicos que compuseram a amostra desta pesquisa foram em número de 22 , sendo que $81,8 \%$ desses periódicos eram Qualis A (Nac.-68,18\%) (Int. -13,63\%), o que denota a boa qualidade dos artigos pesquisados. Com relação à autoria, um fato que chamou a atenção foi que, no Brasil, ainda há uma tendência à autoria individual, contrariamente ao que ocorre no exterior. Pensando sobre tal situação, podese levantar a hipótese de que historicamente ainda se valoriza, em termos pessoais, mesmo de status social, a autoria individual vinculada à autoria de livros, sendo tal fator um indício de atraso no processo de pesquisa que está sendo corrigido, em parte com a formação dos grupos de pesquisa, do diretório do CNPq.

Quanto ao papel das associações científicas, Witter (2007) diz que para atingir suas metas e cumprir os objetivos esperados, as mesmas precisam cumprir vários papéis, sendo o principal o de estímulo à produção científica para o que recorre usualmente à promoção de eventos, concursos, constituição de grupos de pesquisa, organização de redes sociais de seus grupos. Outro papel é a manutenção de banco de dados e publicações. Provavelmente a publicação é que tem efeito mais duradouro e potencial para estimular a produção.

Um fato observado foi que a grande maioria dos autores dos artigos estão vinculados a instituições, e 
pertencem a grupos de pesquisa. O que leva a pensar que o fato de estar vinculado a grupos de pesquisa ou instituições é com certeza um incentivo para a produção de pesquisas.

Quanto ao tipo do trabalho, um dado importante a ser ressaltado é que $60 \%$ dos artigos serem de cunho teórico, o que vai contra o que se observa na literatura internacional onde a maioria da produção vinculada à pessoa do terapeuta é empírica. Tal fato pode estar associado ao desenvolvimento da psicologia no Brasil, em que a psicanálise continua tendo forte influência. A ênfase nas construções teóricas tem levado, historicamente, psicanalistas a resistirem a pesquisas baseadas em evidências empíricas, usualmente mais aceitas por terapeutas de orientação cognitivo-comportamental e behavioristas. Como as variáveis do terapeuta são bastante estudadas pelos psicanalistas, sob a égide da contratransferência, isso fez com que houvesse esse incremento nos resultados, pois a forma de muitos analistas verem a questão da pesquisa é associar questões teóricas com um ou outro caso clinico para ilustrar, não havendo preocupação com a mensuração efetiva dos dados. Outra questão a esse respeito é a tradição da psicologia, no Brasil, onde encontra-se que a produção de artigos mesmo em outras áreas (Psicologia Escolar, por exemplo) está bastante ligada à teorias e não a pesquisas empíricas.

Com relação ao que se encontrou em traços observáveis, onde a literatura internacional descreve sexo do terapeuta, faixa etária ou idade do terapeuta e etnia, o que se teve nos artigos brasileiros foi geralmente menção em um ou outro ponto do artigo ao sexo, idade ou etnia. Nenhum artigo foi resultado de pesquisa especificamente sobre essas variáveis, o que realmente contrasta com a literatura internacional, onde essas variáveis levam os pesquisadores a elaborarem pesquisas com os mais diferentes desenhos para mensurálas, já que o terapeuta é visto como um, senão o principal, componente do processo terapêutico.

$\mathrm{Na}$ literatura internacional, a respeito do sexo do terapeuta como variável que interfere nos resultados de terapia, Beutler et al. (2004) encontraram um significante, mas pequeno efeito favorecendo as terapeutas mulheres, já Patee e Farber (2008) encontram um dado um pouco diferente - pacientes mulheres têm maior stress ao serem atendidas por terapeutas mulheres. O fato denota que ao contrário do Brasil, onde a variável é na maioria das vezes apenas mencionada, existe uma preocupação em relação à pesquisa empí- rica sobre cada uma das variáveis estudadas acerca do terapeuta, e que muitas vezes os resultados surpreendem até mesmos os pesquisadores.

É interessante pensar que, ainda dentro dos traços observáveis, etnia ou raça foram pouquíssimo citadas. A literatura internacional diz que existe um efeito significativo nos resultados terapêuticos quando pacientes e terapeutas são da mesma origem étnica. A American Psychological Association (APA-2007) inclusive elaborou um guia já em 1990 sugerindo posturas e formas de trabalho para treino sensitivo cultural dos terapeutas. Tal fato mostra que há uma preocupação, já há um bom tempo nos Estados Unidos e outros países com o atendimento de pessoas de raça, etnia e culturas diferenciadas, o que não parece ser uma preocupação no Brasil, onde temos uma diversidade étnica e cultural grande.

É possível que no Brasil, mais do que a etnia do psicoterapeuta, a diferença de nível educacional entre ele e o paciente possa ser relevante. A experiência clínica do autor da presente pesquisa com pacientes de camadas socioeducacionais muito baixas sugere que os pacientes tendem a se colocar numa posição bastante submissa frente ao terapeuta, atitude que pode induzi-lo a uma postura "paternal" em relação ao paciente. Neste contexto, a psicoterapia tende a ser mais diretiva. Outra característica deste tipo de paciente é a de que costumam ter um repertório verbal reduzido, ou utilizar expressões verbais para nomearem suas emoções e dores utilizando a expressão "doença dos nervos", ou "estar atacado dos nervos", por exemplo.

$\mathrm{O}$ fato levantado no parágrafo anterior leva a pensar que no Brasil, a preocupação dos psicólogos clínicos acontece mais em relação aos grupos de baixo ou nenhum poder aquisitivo (independente de raça) que à questão de raça ou etnia (embora $45 \%$ da população seja composta por afro-descendentes). Isso pode ser observado pela quantidade de artigos (não apenas os objetos de estudo do presente artigo), que tratam da angustia ou desconforto encontrado pelos psicólogos que trabalham nos serviços públicos de saúde, onde as teorias de sua época de formação não têm respostas para questões que na maioria das vezes são sociais.

No artigo de Castro (2005), pertencente à amostra da pesquisa, há o relato da experiência do psicólogo inserido no ambulatório público, comprometido com trabalho multidisciplinar, situando que em seu trabalho percebia que não somente os pacientes depositavam um saber sobre aquilo que os afligia no psicólo- 
go, mas também os próprios profissionais de outras áreas faziam o mesmo. Ainda sobre a inserção do psicólogo em instituições, Monteiro e Queiroz (2006), ao trabalharem com a questão da clínica das psicoses em instituições de saúde mental, dizem que o trabalho dos analistas nas instituições deve ser inventado, cotidianamente, devido às variáveis que atravessam sua prática. Dizem também da importância da participação do analista na equipe, destacando algumas contribuições da escuta analítica em uma prática feita por muitos.

Segundo pesquisa do Conselho Federal de Psicologia (CFP) realizada com psicólogos brasileiros, discutida por Dutra (2004); o que mais caracterizou a saída da clínica de seu modelo tradicional foi sua inserção na saúde pública, com o terapeuta ou psicólogo clínico passando a atuar em hospitais e ambulatórios gerais e psiquiátricos, nas escolas, nas unidades básicas de saúde, organizações e creches, onde são empreendidas ações ligadas à saúde.

Dentre o que foi encontrado para o presente trabalho, observa-se que no Brasil não existem pesquisas em número suficiente para sustentar um periódico que trate especificamente de pesquisas voltadas à psicoterapia; os artigos que trazem pesquisas se diluem em periódicos que tratam da psicologia, psiquiatria ou psicanálise.

Os dados apontaram para uma tendência crescente entre os autores de orientação cognitivo-comportamental e comportamental, em focalizar as reações emocionais do terapeuta e à necessidade de compartilhá-las ou não com o paciente. A autoexposição do terapeuta, ainda que um tema já bastante discutido na literatura internacional, começa a ganhar espaço na literatura brasileira.

Um dado não encontrado na literatura nacional, mas pesquisado na literatura internacional e que se acredita ser passível de realização de pesquisas no Brasil foi o de que todas as psicoterapias são efetivas. Os tratamentos se equivalem (Beutler et al., 2004).

Muito se encontra na literatura internacional, no que diz respeito a gênero sobre o tratamento vinculado à população GLBT (Gays, Lésbicas, Bissexuais e Transexuais) e variáveis do terapeuta; causando estranheza o fato de no Brasil, embora exista um movimento de gays e lésbicas até bem fortalecido, com passeatas e busca de direitos civis, não haver sido encontrado nenhum artigo sobre o tema. O que leva a pensar que talvez o fato de grande maioria dos artigos serem vinculados a uma leitura psicanalítica, e dentro da psicanálise e suas instituições a homossexualidade assumida (não a latente) pode ser vista como uma perversão do sujeito.

Outra questão a ser levantada foi o fato da pouquíssima utilização pelos terapeutas brasileiros de manuais. Sendo interessante que os manuais formaram uma geração de terapeutas no exterior, que em seguida entrou num processo de questionamento sobre os mesmos, preterindo-os e buscando a supervisão como melhor forma de aquisição de competência do terapeuta. No Brasil, parece não ter acontecido esse fato, sendo que a aprendizagem da técnica passa quase que exclusivamente pela supervisão.

O que foi expresso no parágrafo anterior parece ter uma explicação ligada à formação teórica, pois se grande parte dos terapeutas buscam a psicanálise como embasamento de sua formação, o aprendizado desta passa pela leitura das obras de Freud, o que dá uma visão panorâmica de como conduzir os atendimentos. Algumas instituições de ensino (leia-se professores do curso de psicologia) já quase não priorizam nem mesmo essa leitura, passando diretamente ao estudo de Lacan sem esse passo inicial.

Dentre os artigos com direcionamento psicanalítico, parece haver um consenso que a formação do psicanalista passa pela supervisão, estudo teórico e busca de análise pelo próprio terapeuta, é o caso de: Bernardes (2002), Macedo e Falcão (2005), Padilha (2005), Pereira (2005), Pimentel e Vieira (2005), Zaslavsky e Santos (2005).

Um fato que causou surpresa foi encontrado na literatura internacional, na revisão de Beutler et al. (2004), quando se conclui que a idade do terapeuta ou a similaridade da idade do paciente e terapeuta contribui significativamente para o resultado do tratamento. O que leva a pensar na questão transferência e principalmente contratransferencial, onde os interesses de pessoas de idades próximas são semelhantes. Por exemplo, se tenho quarenta anos é bem mais interessante como terapeuta atender alguém que está na faixa de 30 a 50 anos que atender alguém de digamos 14 anos, pois minha compreensão do que a pessoa esta vivenciando tem proximidade com situações que também eu posso estar passando ou poderia ter passado.

Uma questão interessante a ser pensada e bastante encontrada na literatura nacional e internacional está 
ligada a valores do terapeuta, embora haja grande dificuldade para definirem-se valores, estes parecem remeter a um mito que se criou a respeito da pessoa do terapeuta (e também do cientista) acerca da neutralidade. $\mathrm{O}$ fato de muitos artigos terem apontado que não existe a neutralidade é bastante interessante; pois o terapeuta é pessoa, talvez uma pessoa um pouco melhor habituada a lidar com sua subjetividade, mas pessoa que está também à mercê da existência e que tem stress, problemas financeiros, situações ligadas à saúde, religião (ou ausência da mesma), alegrias e tristezas como qualquer outro ser humano.

Ceitlin et al. (2003) dizem que os psicoterapeutas são normalmente identificados como agentes de mudança das atitudes, crenças e estilo de vida dos seus pacientes. Frente a isso, a sociedade sempre expressou uma preocupação de que o terapeuta exerça uma influência indesejada sobre os pacientes. Os pesquisadores, no entanto têm visto a psicoterapia como um processo, no qual os valores do terapeuta são ingredientes importantes. Segundo as autoras, alguns estudos têm confirmado que os valores dos terapeutas diferem de forma substancial dos valores do homem comum. Terapeutas são, em geral, mais permissivos na expressão sexual, na expressão de pensamentos, na autonomia de valores e no crescimento pessoal, enquanto desvalorizam submissão à autoridade e a Deus. Estas diferenças, somadas com o poder potencial que os terapeutas possuem sobre seus pacientes, sublinham a necessidade de avaliar a importância dos valores do terapeuta nos resultados da terapia.

Um outro fator digno de menção foi o encontrado na literatura internacional e não encontrado em nenhuma pesquisa no Brasil diz respeito ao trabalho do terapeuta com pessoas idosas, onde é dito que os terapeutas têm uma visão negativa e estereotipada dos pacientes mais velhos (idosos) (Dazinger \& Welfel, 2000; Ivey, Wieling \& Harries, 2000; Meeks, 1990). $\mathrm{O}$ fato de não se encontrar nenhuma pesquisa no Brasil que faça a relação da pessoa do terapeuta com o atendimento de idosos leva a pensar que talvez esse campo de atendimento ainda não tenha tradição; isso é não existem muitos trabalhos do psicólogo ou psiquiatra com essa população no Brasil e se existe parece que ainda não houve uma sistematização de pesquisas ou mesmo de teorização a respeito. Com relação ao idoso e pesquisa cientifica, Witter e Ferreira (2005) dizem que embora já existisse preocupação sistemática com esse segmento da população no séc. XVIII e
XIX, é especialmente nas últimas décadas do século $\mathrm{XX}$ que o interesse de varias áreas sobre o assunto cresceu. Em parte devido ao significativo aumento de idosos em todos os países como efeito dos avanços científicos e tecnológicos que ampliaram a duração da vida humana. Em 2000, já se contava, no Brasil com $12,6 \%$ da população. As autoras dizem que embora a pesquisa sobre idosos no Brasil venha crescendo ela é muito pulverizada tematicamente. $\mathrm{O}$ estudo do idoso ainda carece de referências conceituais sólidas, critérios claros, e instrumental específico. Dentro da situação colocada por Witter e Ferreira (2005) cabe aqui a indicação para pesquisadores realizarem estudos sobre $o$ assunto enfocando o atendimento de idosos e a pessoa do terapeuta.

Um fato importante, ligado à formação de psicólogos é a existência de muitos cursos de psicologia onde não se dá ênfase à pesquisa, não formando profissionais que se pautem na pesquisa como background de seu trabalho. Embora em algumas instituições de ensino a participação do aluno, já desde sua formação acadêmica seja vinculada a grupos de pesquisa, o que pode fazer com que o panorama mude futuramente.

Apesar de a produção não ser muito volumosa, há trabalhos relevantes que trazem contribuições que merecem reflexão. Quanto às pesquisas, apesar de ainda serem relativamente pouco numerosas, indicam um movimento que deverá se acelerar nos próximos anos, com as exigências dos periódicos, e a avaliação Qualis, com o papel do Diretório de pesquisadores do CNPq. Pode-se pensar que estamos num momento bastante promissor em que novos rumos estão se descortinando.

Como conclusão, é importante expressar que o presente trabalho leva a uma gama imensa de variáveis que podem vir a ser passiveis de realização de pesquisas, sendo que muito pouco se tem no Brasil a respeito. Podendo ser nomeados alguns aspectos com relação às variáveis da pessoa do terapeuta como: idade, sexo, gênero, quantidade de treinamento, supervisão, bem estar emocional, valores atitudes e crenças, posicionamento teórico, idosos, etnia, entre outros, como possibilidades de novas pesquisas.

\section{REFERÊNCIAS}

American Psychological Association (2007). APA Guidelines for providers of psychological services to ethnic, linguistic, and culturally diverse populations. Washington, DC. Retirado em 14 de maio de 2007, de http://www.apa.org 
Bernardes, A.C. (2002). A segunda regra fundamental: Um comentário sobre o Ferenczi de Lacan. Agora, 5(2), 311-316.

Beutler L. E., Machado, P. P., \& Neufeldt, S. A. (1994). Therapists variables. In A. E. Bergin \& S. L Garfield (Eds.), Handbook of psychotherapy and behavior change (pp. 229-269). New York: John Wiley \& Sons.

Beutler, L. E., Malik, M., Alimohamed, S., Harwood, T. M., Talebi, H., Noble, S. \& Wong, E. (2004). Therapist variables. In M. J. Lambert (Eds.), Bergin and (Garfield's Handbook of psychotherapy and behavior change (pp. 227-306). New York: John Wiley \& Sons.

Braga, G. L. B, \& Vandenbergue, L. (2006). Abrangência e função da relação terapêutica na terapia comportamental. Estudos de Psicologia, 23, 307-314.

Castro, S. L. S. (2005). Reflexões sobre a clínica no ambulatório público. Psicologia: Ciência e Profissão, 25, 462-471.

Ceitlin, L. H. F, Wiethaeuper, D., \& Goldfred, P. R. M. (2003). Pesquisa de resultados em psicoterapia de orientação analítica: Efeito variáveis do terapeuta. Revista Brasileira de Psicoterapia, 5, 81-95.

Dazinger, P. R., \& Welfel, E. R. (2000). Age, gender, and health bias in counselors: An empirical analysis. Journal of Mental Health Counseling, 22, 135-149.

Dutra, E. (2004). Considerações sobre as significações da psicologia clínica na contemporaneidade. Estudos de Psicologia ( $N a$ tal), 9, 381-387.

Fleiss, J. L. (1981). Statistical methods for rates and proportions. New York: John Wiley.

Foster, J. L., Lichtenberg, J. W., \& Peyton, V. (2007). The supervisor attachment relationship as a predictor of the profesional development of the supervisee. Psychotherapy Research, 17, 343-350.

Hess, S. A., Knox, S., Schultz, J. M., Hill, C. E., Sloan, L., Brandt, S., Kelley, F., \& Ioffman, M. A. (2008). Predoctoral interns' nondisclosure in supervision. Psychotherapy Research, 18, 400-411.

Ivey, D. C., Wieling, E., \& Harris, S. M. (2000). Save the young the elderly have lived their lives: Ageism in marriage and family therapy. Family Process, 39, 163-175.

Lambert, M. J. (Eds.) (2004). Bergin and Garfield's Ilandbook of psychotherapy and behavior change. New York: John Wiley \& Sons.

Lambert, M. J. (2007). Presidential address: What we have learned from a decade of research aimed at improving psychotherapy outcome in routine care. Psychotherapy Research, 17, 1-14.

Macedo, M. M. K., \& Falcão, C. N. B. (2005). A escuta na psicanálise e a psicanálise da escuta. Psychê, 15, 65-76.

Marucco, N. C. \& Marucco, A.V. (2004). A prática analítica atual e a problemática do poder. Revista de Psiquiatria do Rio Grande do Sul, 26, 259-267.

Meeks, S. (1990). Age bias in the diagnostic decision-making behavior of clinicians. Professional Psychology: Research and Practice, 21, 279-284.
Monteiro, C. P., \& Queiroz, E. F. (2006). A clínica das psicoses em instituições de saúde mental. Psicologia Clínica, 18, 109121.

Padilha, M. T. M. (2005). Supervisão: O ato da palavra. Estudos de Psicanálise, 28, 103-110.

Pattee, D., \& Farber, B. A. (2008). Patients' experiences of self-disclosure in psychotherapy: The effects of gender and gender role identification. Psychotherapy Research, 18, 306-315.

Pereira, D. (2005). Transferências na clínica da psicossomática. Pulsional [Número especial], 101-115.

Pimentel, D., \& Vieira, M. J. (2005). Perfil e saúde mental de psicanalistas. Psychê, 15, 155-166.

Roussos, A. J., Lissin, L. B., \& De Duarte, A. L. (2007). The importance of the theoretical framework in the formulation of clinical inferences in psychotherapy. Psychotherapy Research, $17,535-543$

Smith, T. B., Bartz, J., \& Richards, P. S. (2007). Outcomes of religious and spiritual adaptations to psychotherapy: A metaanalytic review. Psychotherapy Research, 17, 643-655.

Timulak, L. (2007). Identifying core categories of client-identified impact of helpful events in psychotherapy: A qualitative metaanalysis. Psychotherapy Research, 17, 305-314.

Tryon, G. S., Blackwell, S. C., \& Hammel, E. F. (2007). A metaanalytic examination of client-therapist perspectives of working alliance. Psychotherapy Research, 17, 629-642.

Wade, N. G., Worthington Jr., E. L., \& Vogel, D. L. (2007). Effectiveness of religiously tailored interventions in Christian therapy. Psychotherapy Research, 17, 91-95.

Williams, D., \& Levitt, I. M. (2008). Clients' experiences of difference with therapists: Sustaining faith in psychoterapy. Psychotherapy Research, 18, 256-270.

Witter, G. P. (2007). Importância das sociedades/associações científicas: Desenvolvimento da ciência e formação do profissional pesquisador. Boletim de Psicologia, 57, 1-14.

Witter, G. P., \& Ferreira, A. P. (2005). Idoso e leitura: Análise da produção cientifica arrolada na PsycINFO. In G. P. Witter (Ed.), Metaciência e psicologia (pp. 155-170). Campinas: Alínea.

Yoshida, E. M. P., Santeiro, T. V., Santeiro, F. R. M., \& Rocha, G. M. A. (2005). Psicoterapias breves psicodinâmicas: Características da produção científica nacional e estrangeira (1980/ 2003). Psico-USF, 10, 51-59.

Zaslavsky, J., \& Santos, M. J. P. (2005). Contratransferência em psicoterapia e psiquiatria hoje. Revista de Psiquiatria do Rio Grande do Sul, 27, 293-301. 